\title{
The research of the freezing and thawing process of the foundations with the use of season and cold-producing devices
}

\author{
Sergey Kudryavtsev ${ }^{1 *}$ and Anastasia Borisova ${ }^{1}$ \\ ${ }^{1}$ Far Eastern State Transport University, Serysheva, 47, Khabarovsk, 680021, Russia
}

\begin{abstract}
The thermal effect from the foundation into the permafrost was researched by the numerical modeling in the software "FEMmodels". The pile foundation and slab structures were modeled with and without the use of season-al-cooling devices. The research of the foundation influence on the permafrost was performed in the full-year cycle of air temper action to the ground.
\end{abstract}

\section{Introduction}

The best part of the Russian Federation is dominated by permafrost including the regions of the Far North and the Arctic. The Far North and the Arctic are ones of the richest regions of Russia by their natural resources. Due to hard climate and complicated geological conditions, construction in these regions is difficult. This fact makes construction objects one of the most expensive material and labor-intensive projects. However, this is not an excuse to refuse construction in this territory.

For the permafrost, the negative temperature fluctuations in the upper part of the layer to the boundary of zero amplitude of seasonal oscillations, the appearance of subsidence, thawing of the layer with a change in the thermal regime on the surface are common.

Therefore, one can say that the preservation of the permafrost soils stated under the spot of construction is the actual project.

\section{The subject of the research}

The great attention is paid to the development of territories of the Far North and the Arctic. It is connected to the occurrence of a huge quantity of gas hydrates in these areas. The gas hydrates are the new vast source of natural gas, which is capable to provide the growing world economy's needs.

For the implementation of the gas hydrates production, their processing, and transportation, It is necessary to have human resources living in this territory for an implementation of the gas hydrates production.

\footnotetext{
*Corresponding author: olgakudr56@mail.ru
} 
However, extreme climatic conditions of the Far North and the Arctic make it difficult for people to live there. The construction of the accommodation buildings in the Far North and the Arctic is one of the most difficult tasks in the buildings industry. Housing must meet the requirements of standardizing and provide all comfort conditions for employees and their families.

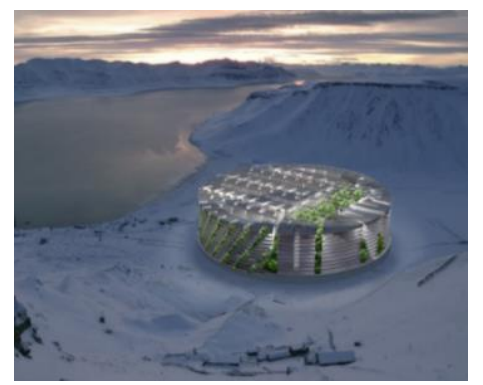

Fig. 1 The helio - cluster "Polar Oasis"

In Russian government's hearing "The New Generation Housing for the Russian Family" the Institute of Geoloculture has presented the project "The helio - cluster "Polar Oasis". The helio - cluster "Polar Oasis" is relating to spatial planning module, including the full range of city functions such as parks, water parks, mandarin groves, sports halls, offices. This complex will provide comfortable accommodation of 3000 people in one building; it is applicable for the development of the Far North territories. The complex covers an area of 3 hectares. The structural skeleton of the building has a cylindrical shape with a glass dome. The diameter of the building is $195 \mathrm{~m}$, the height is 50 meters, the number of floors is 13 .

\section{The purposes of the research}

- The research of temperature impact from the building to the permafrost.

- The choice of foundations construction solution in the territory of permafrost occurrence, which shuts out the thawing processes of permafrost because of temperature action subject. This type of construction must take into account technical and economic indexes permafrost-geologic temperature conditions.

\section{The foundation construction}

\subsection{The deep foundation}

The traditional option of the construction of the underground building part in permafrost areas is the pile foundation. It transfers the load from the building to an incompressible stratum of frozen soil.

The proposed deep foundation construction is the reinforced concrete piles with monolithic reinforced concrete grillage. To reduce the thermal impact of the building to the ground, the guard space is carried out: the floor of the building ground floor is raised by 2 meters above the ground level. 


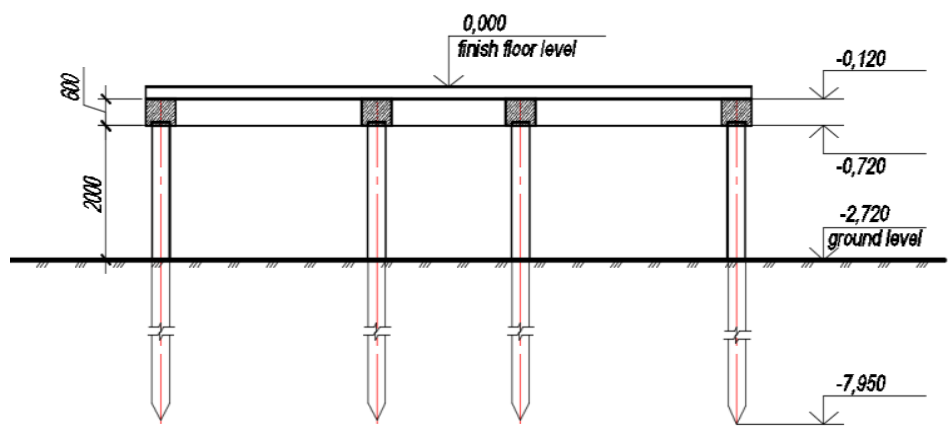

Fig.2 The pile foundation construction

\subsection{The shallow foundation}

The shallow foundation construction is the reinforced concrete slab 2 meters thick.

The base of the building is embedded above the ground level by $300 \mathrm{~mm}$

As the protection of the foundation, it is considered the variant of laying insulation expanded - polystyrene plates in the bedding sand. The laying insulation expanded-polystyrene plates will reduce the temperature influence on the ground.

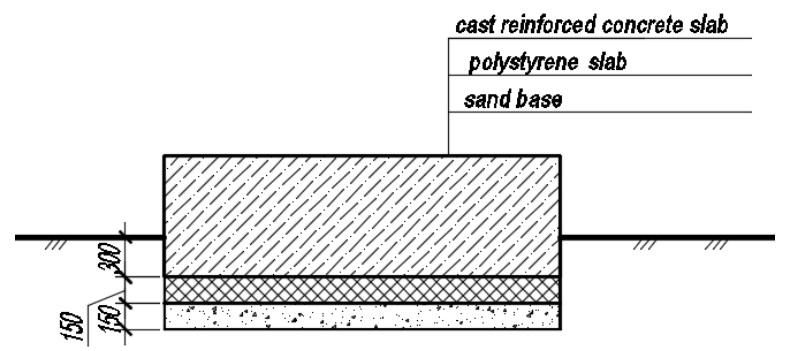

Fig.3 The shallow foundation construction

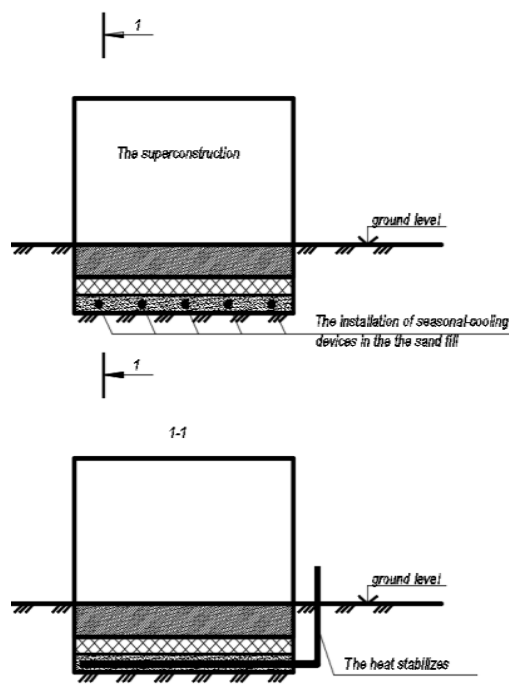

Fig.4 The computational scheme of the device of the foundation monolithic plate with the use of the NOHP system 
The improvement of the foundation slab construction:

The improvement of the foundation slab construction: The installation of seasonal-cooling devices is carried out under the foundation slab. The heat stabilizes are predesignated for cooling and freezing permafrost to increase its bearing capacity and reduce the thermal influence of the building on the ground. A horizontal natural-effective cooling system is used as the temperature stabilizer. It allows freezing the soil under the building.

The NOHP system is a sealed heat transfer device that automatically operates in winter due to gravity and a positive temperature difference between the ground and outside air.

The system consists of two main elements:

1. Horizontal cooling pipes located in the ground of the base are used for the circulation of refrigerant and subsequent priming of the soil.

2. Condenser block is located on the ground surface. In the condenser block due to natural convection and gravity, there is a condensation of vapors of coolant and its further recirculating through the system.

The NOHP system operates without electricity in automatic mode. During the winter, cooling pipes transfer heat from the ground to the coolant. The refrigerant passes from the liquid phase to the vapor phase. The steam moves towards the condenser unit, where it passes into the liquid phase again giving off heat through the fins to the atmosphere.

In the summertime, the system automatically stops operating, as the outdoor temperature becomes higher than the ground temperature. Fig.4 - The computational scheme of the device of the foundation monolithic plate with the use of the NOHP system

\section{Analysing of the foundation constructions}

Numerical modeling was performed the research of the foundation influence on the permafrost by "Termoground" software package in the full-year cycle of air temper action to the ground.

This complex geotechnics task is solved in two stages. First, the thermotechnical problem is solved, as a result, the temperature and humidity fields are determined for each period of time. The second step is to solve the problem of determining the stress-strain state of the soil massif in the process of freezing and thawing.

General equation describing the freezing and thawing processes for a transient thermal regime in a three-dimensional soil space can be expressed as follows:

$$
C_{t h(f)} \rho \frac{\partial T}{\partial t}=\lambda_{t h(f)}\left(\frac{\partial^{2} T}{\partial x^{2}}+\frac{\partial^{2} T}{\partial y^{2}}+\frac{\partial^{2} T}{\partial z^{2}}\right)+q_{V}
$$

where $C_{t h(f)}$ - specific heat of soils (frozen or thawed), J/kgK; $\rho$-soil consistency, $\mathrm{kg} / \mathrm{m}^{3}$; $\mathrm{T}$ - temperature, $\mathrm{K} ; \mathrm{t}$ - time, $\mathrm{c} ;{ }^{\lambda_{\text {th }(f)}}$ - thermal conductivity of soil (frozen and thawed), $\mathrm{W} / \mathrm{mK} ; \mathrm{x}, \mathrm{y}, \mathrm{z}$ - coordinates, $\mathrm{m}$; qv- internal heat source capacity, $\mathrm{W} / \mathrm{m}^{3}$.

\subsection{Analyzing of the temperature influence of the pile foundation on the ground}

The temperature of the permafrost remains negative.

The main condition for saving a negative temperature in the permafrost is to cover the space between the ground and the level of grillage with metal grilles for a summer period to prevent 
sunlight from entering. If it doesn 't carry out this condition, the base under the building will be thaw out, forming the cup of thawing.

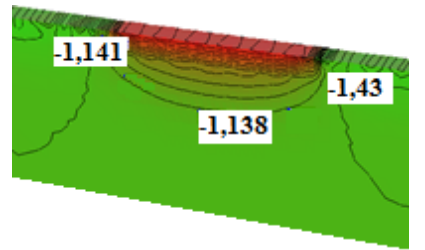

Fig.5 - The temperature distribution in the zone of influence of piling foundation on the ground

\subsection{Analysing of the temperature influence of the foundation slab with using the natural-effective cooling system}

The temperature in the zone of foundation influence has negative values throughout the full-year period. The thawing cap under the foundation didn't form, so the heat stabilizers can be used as a protection against the temperature influence of the building on the permafrost soil base

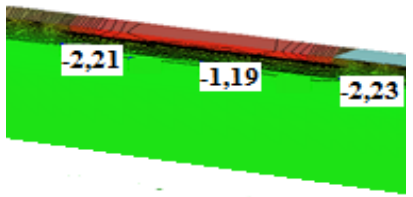

Fig.6 - The temperature distribution in the zone of the foundation slab influence on the ground with the use of the NOHP system

\section{Conclusion}

1. The problem of the negative temperature maintaining of permafrost is relevant for industries and housing and communal services.

2. This work was carried out for the development of the building underground part for the project proposed by the RF Government "Helio-cluster" Polar Oasis " where the variants of the deep and shallow foundations for the helio-cluster "Polar Oasis" were proposed.

3. Analysis of calculations in the FEMModels software package of the thermal effect of the building's foundations on the base permafrost soils was carried out: ing;

3.1. The use of seasonal-cooling devices ensures the protection of the ground from thaw-

3.2. Given the engineering-geological conditions, climatic characteristics, mechanical properties of permafrost, it is possible to construct both pile and slab reinforced concrete structures using NOHP.

In connection with the change in the average annual temperature, frozen rocks thawing was recorded. The widespread degradation of permafrost is noted: an increase in the average annual temperatures of frozen soils in the negative range and thawing them from the surface.

The classical version of foundations with the device of blowouts does not take into account unforeseen thermal influences on permafrost soils, unlike seasonal-cooling devices that allow controlling the temperature regime of soils 


\section{References}

1. S.A. Kudryavtsev, U.B. Berestyanyy, T.U. Valtseva, et.al. 1st International conference on new developments in geoenvironmental and geotechnical engineering. November 911, University of Incheon. Korea. 423-427 (2006)

2. S.A. Kudryavtsev, T.U. Valtseva, et.al. 9th International Conference on Permafrost (NICOP) and the field trip followed at the University of Alaska Fairbanks in Fairbanks, Alaska. June 29-July 3, USA, 323-324 (2008)

3. S.A. Kudryavtsev, et.al. MATEC Web of Conferences, 106 (2016)

4. S.A. Kudryavtsev, Kazharsky A.V., et.al. Embankment on permafrost Eastern polygon of Baikal-Amur Mainline. International Scientific Conference on Transportation Geotechnics and Geoecology, Saint Petersburg, May 17-19, 2017. Russia. V.189, P. 774-782.

5. J. Kaikko, A. Mankonen, E. Vakkilainen, V. Sergeev, Energy Procedia 120, 572-579 (2017), doi:10.1016/j.egypro.2017.07.172

6. A. Fedyukhin, I. Sultanguzin, A. Gyul'Maliev, V. Sergeev, Eurasian Chemico-Technological Journal 19, 245-253 (2017), doi:10.18321/ectj669

7. V.G. Kiselev, V.V. Sergeev, E.N. Rouzich. Influence of the electric double-layer capacitance at the rate of corrosion at the phase interface. Corrosion Reviews, 35(1), (2017), pp. 47-51. doi.org/10.1515/corrrev-2016-0049 